\title{
SHARING KNOWLEDGE MELALUI SOSIALISASI PENGELOLAAN SAMPAH PLASTIK DI PROPINSI SULAWESI TENGGARA
}

\author{
Laode Muhamad Fathun \\ UPN Veteran Jakarta \\ e-mail: laodemuhammadfathun@upnvj.ac.id
}

\begin{abstract}
This paper writes about the management of plastic waste in Southeast Sulawesi Province, a case study in Muna and Buton Regencies. This activity is in the form of sharing the author's knowledge with the Indonesian City Diplomacy Community partners in 2020-2021. This activity uses observation, socialization and interview methods to build the community's mindset. The author found that plastic waste management activities in Muna and Buton have been maximized. This is done because the community upholds the value of morality as a form of social responsibility. Cultural values as the foundation of society in protecting the sea. This means that the authors in sharing knowledge only confirm community activities and provide little knowledge to the community. The community is very aware of protecting the sea as part of their identity, branding, and representation of toughness. The sea is the ancestral medium of the community that must be preserved as a form of appreciation. Because the sea is the source of the local community's economy. So, if the nature is damaged, it will damage the economy of the surrounding community. Dissemination and sharing of knowledge are effective because the community does not need to be equipped with much in protecting the sea. Cultural experience and moral principles guide them to be able to make the sea an asset of the future. The sea is the way humans relate to nature, natural resources.
\end{abstract}

Keywords: Sharing, Knowledge, Muna, Buton, Sea

Sharing Knowledge melalui Sosialisasi Pengelolaan Sampah Plastik di Propinsi Sulawesi Tenggara 


\begin{abstract}
ABSTRAK
Paper ini menulsikan tentang pengelolaan sampah plastic di Propinsi Sulawesi Tenggara studi kasus di Kabupaten Muna dan Buton. Kegiatan ini berbentuk sharing knowledge penulis Bersama mitra Komunitas Diplomasi Kota Indonesia pada tahun 2020 -2021. Kegiatan ini menggunakan metode observasi, sosialisasi dan wawancara dalam membangun mindset masyarakat. Penulis menemukan bahwa kegiatan pengelolaan sampah plastic di Muna dan Buton sudah maksimal. Hal ini dilakukan karean masyarakat menjunjung tinggi nilai moralitas sebagai bentuk tanggung jawab social. Nilai kebudayaan sebagai fondasi masyaraakat dalam menjaga laut. Artinya penulis dalam sharng knowledge hanya mengkonfirmasi aktifitas masyarakat dan sedikit memberi pengetahuan kepada masyaraakat. Masyarakat sudah sangat paham dalam menjaga laut sebagai bagian dari identitas, branding, representasi ketangguhan. Laut adalah media leluhur maysrakat yang harus dilestarikan sebagai bentuk apresiasi. Karena laut menjadi sumber ekonomi masyarakat setempat. Sehingga, jika dirusak alamnya maka akan merusak ekonomi masyarakat sekitar. Sosialisasi dan sharing knowledge berjalan efektif karena masyarakat tidak perlu dibekali banyak dalam menjaga laut. Pengalaman kebudayaan dan prinsip moral menuntun mereka agar bisa menjadikan laut sebagai asset masa depan. Laut adalah cara manusia berhubungan dengan alam, sumber daya alam.
\end{abstract}

Kata Kunci: Sharing, Knowledge, Muna, Buton, Laut

\title{
PENDAHULUAN
}

ASEAN saat ini disibukan dengan impor sampah dari beberapa negara maju.Impor sampah tersebut tentunya memiliki konsekuensi ekonomis dan higinis (lingkungan). Beberapa negara ASEAN yang terkena dampakimporsampah diantaranya adalah Malaysia, Filipina, Thailand, dan Vietnam. Hal yang samadi alami oleh Indonesia yang justru menjadi bagian impor sampah negara-negara maju seperti Amerika, Negara-negara Eropa serta Australia.

Lebih lanjut, negara-negara ASEAN seperti Filipina yang telah mengembalikan 69 kontainer (sekitar 1.500 ton) yang mengandung kontaimen atau bahan berbahaya(republika.com/31/05/2019).. Hal yang 
sama dilakukan oleh Indonesia terhadap Australia, konsekuensinya adalah Australia merasa dirugikan dan mengajukan protes kepada Indonesia karena menolak impor sampahnya. Indonesia sendiri sepakat bahwa impor sampah harus bebas dari bahan berbahaya dan beracun karena memiliki dampak terhadap lingkungan. Asutralia dipaksa mengikuti aturan Indonesia dan Filipina ,apabila tidak melakukan hal tersebut, maka Australia bisa kehilangan pasar di wilayah ASEAN terkhusus Indonesia dan Filipina. Menanggapi hal tersebut, Australia akan berbenah termasuk akan memisahkan sampah impornya menjadi sampah layak daur ulang tidak terkontaminasi dengan bahan beracun dan berbahaya. Australia sendiri tidak menginginkan menggunakan sampah daur ulang untukproduksi barangbarangyanya termasuk kosmetik. Konsekuensinya adalah sampah Australia bisa sampai ke Mojokerto (tempo.com.10/09/2019).

Menurut direktur eksekutif Ecoton, Prigi Arisandi, dikutip dari Channel News Asia, Minggu (7/7/2019), mengatakan bahwa, tingkat kontaminasi mungkin diharapkan murni tidak disengaja, yakni sekitar 2 persen, bukan injeksi sampah yang disengaja untuk dihadapi Indonesia. Tetapi sistem berubah setelah China membuat keputusan bulan Januari 2018 yang menolak sistem daur ulang dunia memasuki China. Lebih lanjut, studi yang dilakukan oleh Greenpeace (Fathun,2019) menerangkan bahwa Indonesia, Malaysia, Thailand, dan Filipina menunjukan kenaikan hasil impor sampah mencapai 171 persen. Malaysia sendiri hasil impor sampah tahun 2018 mencapai 872.897 ton yang naik 300 persen sejak tahun 2016 . Sedangkan Indonesia, jumlahnya melonjak hampir 250 persen hanya dalam 12 bulan, dengan kontributor terbesar adalah Amerika Serikat, Kanada, Italia, Korea Selatan, dan Inggris. Kemudian, nama Presiden Rodrigo Duterte mengembalikan 69 kontanier sampah yang ada di Filipina. Dia berpendampat

Sharing Knowledge melalui Sosialisasi Pengelolaan Sampah Plastik di Propinsi Sulawesi Tenggara 
bahwa tidak akan mentolerir terhadap masuknya sampah dunia. Presiden Rodrigo Duterte menyaksikan di pelabuhan Filipina terdapat 2.400 ton sampah daur ulang yang telah dilabeli (Fathun, 2019).

Menurut Archie Satya Nugroho dari PT. Guna Olah Limbah mengatakan bahwa berhentinya kebijakan Tiongkok terhadap impor sampah selain karena isu lingkungan negara tersebut, kebijakan pemberhentian itu karena mahalnya tipping fee. Di negara-negara maju harga tipping fee sangat mahal sedangkan di negara-negara berkembang sangat murah. Smpah dinegara-negara maju tidak dipergunakan padahal mereka memiliki teknologi yang modern. Beberapa negara ASEAN seperti Filipina yang pernah meengembalikan berton-ton sampah dari berbagai negara maju harus merevisi kebijakan impor sampahnya.Demikian puladengan Malaysia, Thailand termasuk Indonesia. Indonesia sendiri sepertinya harus meniru kebijakan sampah yang dilakukan oleh Tiongkok dimana Tiongkok memberlakukan kebijakan sampah yang sudah tercecah untuk bisa masuk kenegaranya.Tiongkok mewajibkan setiap sampah yang masuk sudah terpisah dengan sampah yang teridentifikasi bahan beracun dan berbahasaya seperti oli, infus, botol kemasan dll(dw.com/17/06/2019) (Fathun, 2019). 


\section{Gambar 1}

Sirkulasi sampah plastik

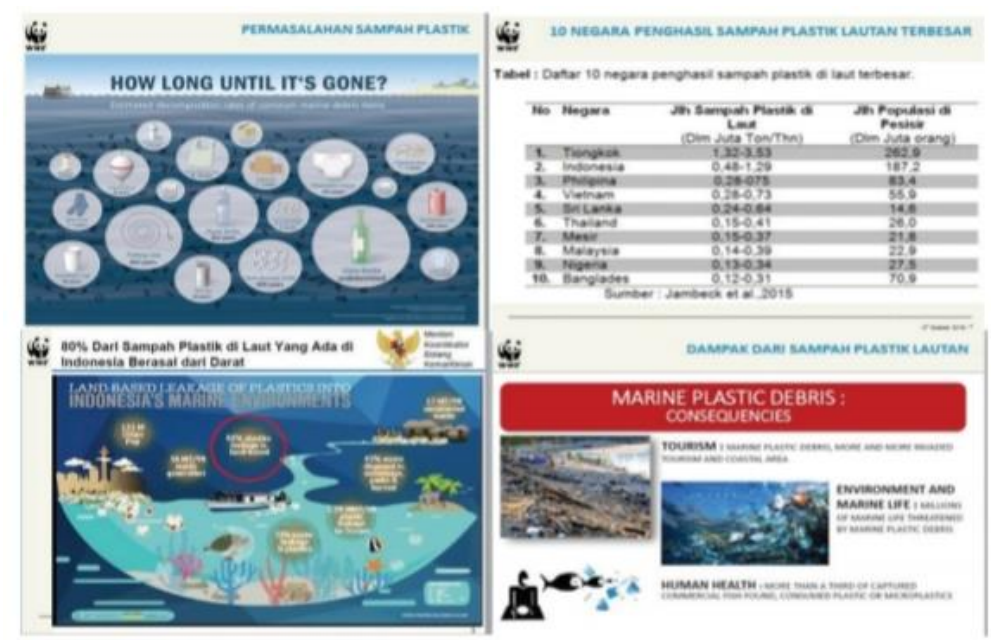

Sumber : (Fathun 2019)

Indonesia sebagai salah satu negara anggota ASEAN juga mendapatkan dampak dari membludaknya smpah plastic. Indonesia mengirim balik 5 kontainer berisi sampah ke AS. Menurut Ditjen Pengelolaan Saampah,Limbah dan B3,, menyatakan bahwa lima kontainer tersebut dikirim melalui pelabuhan Tanjung Perak Surabaya melalui kapal Zim Dalian menuju pelabuhan Seattle, AS yang akan transit terlebih dahulu ke Shanghai Tiongkok. Lima kontainer tersebut tidak sesuai dengan impor yang dilakukan karena dalamkontainer masih bercampur diantaranya adalah sampah rumah tangga, beracun,dan berbahaya. Kontainer juga berisi plastic,impus, oli bekas, dll. Konsekeusni ini tentunya akan sangat berbahaya bagi kesehatan lingkungan (detiknews/14/06/2019).

Indonesia masih menjadi negara penghasil sampah plastik terbesar kedua setelah Tiongkok.Hal ini tentunya membuat citra buruk bagi Indonesia yang selalu identitk dengan budaya sosial yang ramah baik secara sosial maupun terhadap alam. Namun fakta di lapangan membuktikan pengelolaan

Sharing Knowledge melalui Sosialisasi Pengelolaan Sampah Plastik di Propinsi Sulawesi Tenggara 
sampah plastik di Indonesia masih belum optimal terutamadiwilayah pesisir. Konsekuensinya akan berdampak pada lingkungan wilayah tersebut terutamawilayah pesisir yakni kualitas dan kuantitas hasil tangkap di wilayah laut. Wilayah pesisir masih menjadi wilayah yang potenssial sebagai lokasi terakhri pembuangan sampah plastiksecara illegal.Wilayah laut di anggap sebagai lokasi yang luas dan mudah untukmengurai sampah yang berbedadengan dilokasi daratan. Efek buruknya pun seperti bau busuk, higinis, langsung terurai kedalam laut,padahal faktanta tidak demikian. Kejadian-kejadian tersebut justru memperkeruhkualitas laut dan berdampak siginifikan terhada pekonomi kelautan. Presiden Jokowi menuturkan bahwa permasalahan sampah sudah menjadi orientasinya sejak menjadi gubernur. Jokowi melaksanakan rapat terbatas dengan sejumlah Menteri, Gubernur, Bupati dan Walikota untuk menjelaskan masalah sampah. Jokowi mengatakan masalah sampah progresnya melambat atau belum ada progress. Jokowi mengharapkan sampah menjadi salah satu sumber tenaga listrikatau PLTSa sebagai solusis alternative dalam mengelola sampah dengan baik. ( Detik.com.Selasa, 16 Jul 2019 15:09 WIB). Lebih lanjut, Jokowi pada tahun 2017 menyampaikan pidato bawah akan mereduksi sampah plastic di wilayah laut sebesar 30-70 persen sampai 2025. Jokowi menyampaikan haltersebut ketika menjadi pemimpin Retreat G20 Summit Hamburg Jerman 7 juli 2017.

Kekhawatiran situasi nasional terhadap dampak sampah plastik menjadi agendautama Indonesia dalam mengurangi ancaman lingkungan tersebut. Hal ini bukan hanya terkait ancaman nasional saja tetapi komitmen internasional dalam menjaga laut sebagai bagian dari kehidupan manusia. Mengapaplastik begitu popular penggunaannya,karena,sifat material plastic yang kuat, elastis, tahan lama, serta murah menjadikan penggunaan material plastic melampaui sebagian besar materi buatan lainnya. Kurang dari 8,3 
miliar ton plastik telah diproduksi secara massal sejak tahun 1950an. Saat ini diperkirakan laut sudah menampung 150 juta ton sampah plastic dan diprediksi akan menampung 250 juta ton sampah plastic pada tahun 2050. (Gallo, 2018). dalam laporan riset yang dimuat di jurnal Science (2015), tim peneliti yang dipimpin Jenna $\mathrm{R}$ Jambeck dari Universitas Georgia menyatakan sampah plastik yang mengalir ke laut bisa lebih besar. Kalkulasi data dari 192 negara nmenyebutkan Indonesia menempati peringkat kedua dengan produksi sampah plastiknmencapai 3,2 juta ton setelah Tiongkok $(8,8$ juta ton), disusul Filipina (1,9 juta ton), Vietnam (1,8 juta ton), dan Sri Lanka (1,6 juta ton). Sekitar $83 \%$ sampah di Indonesia tidak dikelola dengan baik (Fathun, 2019).

Menurut argumentasi The Economist, Selasa (18/6) bahwa banyaknya impor sampah dibeberapa negara ASEAN termasuk Indonesia akibat kebijakan Tiongkok. Kebijakan Tiongkok berhenti melakukan impor sampah kepada sejumlah negara termasuk AS dan negara-negara Eropa.Tiongkok adalah salah satu negara tersebsar penghasilsampah di dunia bahkan menjadi salah satu negara yang memilikiindistri pengolahan sampah daur ulang tersebsar di dunia. Konsekuensinya adalah sejumlah negara maju tersebut harus mencari konsumen baru untuk bisa membeli hasil sampah plastic mereka. Disisi lainya Tiongkok menyetop hal tersebut dengan akumulasi ekonomi sebesar USD 24 miliar per tahun, sehingga industri manufaktur ini berhenti dan berdampaksosial,ekonomi dan lingkungan juga kepada bebera negara lainnya. Salah satu konsekuensinya adalah terhadap Indonesia (Kumparan18/06/2019) (Fathun, 2019).

Isu lingkungan masih menjai ancaman non tradisional dalam hubungan internasonal. Keamanan lingkungan tentunya akan memiliki dampak terhadap kehidupan sosisl dan ekonomi masyarakat terutama yang

Sharing Knowledge melalui Sosialisasi Pengelolaan Sampah Plastik di Propinsi Sulawesi Tenggara 
tinggal wilayah pesisir. Oleh sebab itu, pengabdian ini akan menjawab persoalan bagaimana pengelolaan sampah plastic berbasi pendekatan budaya di Sulawesi Tenggara tahun 2021. Pengabdian ini dilakukan di Pantai Mutiara Kabupaten Buten Tengah dan Pantai Meleura Kabupaten Muna. Kegiatan ini bermitra dengan Komunitas Akademik Diplomasi Kota Indonesia dalam bentuk ssoalisasi pengetahuan.

\section{OBJEKTIVITAS PENGABDIAN MASYARAKAT}

Beberapa fakta di atas menunjukan pengelolaan sampah plastic di ASEAN dan Asia Pasifik masih sangat buruk. Fakta di atas menunjukan beberapa Negara ASEAN dan bahkan Asutralia dan China kewalahan dalam mengatasi pengelolaan sampaah plastic di Negara masing-masing.Tidak terkecuali Indonesia yang juga menjadi salah satu Negara yang menderita akibat buruknya pengelolaan sampah plastik. Prilaaku budaya masih menjadi faktor dominan dalam buruknya pengelolaan sampah plastic tersebut.Konsekuensinya jelas berembes pada bidang ekonomi dan social. Objektifitas fakta di atas menunjukan keamanan lingkungan belum maksimal di prioritaskan oleh beberapa negara.

Salah satu fakta objektifitas sampah plastic berdampak pada Indonesia adalah buruknya pengelolaan sampah plastic di Kabupaten Wakatobi.wakatobi menjadi salah satu Kabupaten dari Propinsi Sulawesi Tenggara.Wakatobi menjadi salah satu wilayah yang juga menjadi destinasi utama dalam program Kementrian Parwisata RI. Bahkan Wakatobi menjadi wilayah yang didesaain sebagai 10 Bali baru. Keindahan alam pariwisata Kabupaten Wakatobi menjadi destinasi yang menarik bukan hanya bagi wisatawan dalam negeri tetapi wisatawaan luar negeri. Destinasi pantai masih menjadi tujuan wisata utamadi Wakatobi selain destinasi lainya. 
Namun apabila keindahan lingkungan Wakatobi ini tidak dikelola dengan baik maka akan berujung pada konsekuensi pendapatan ekonomi masyarakat dan akan menunjukan prilaku sosialyang kurang baik dimata wisatawan nasional dan internasional.

Salah satu fakta objektif di lapangan yang masih hangat terjadi adalah matinya seekor paus jenis Sperm Wale yang ditemukan mati terdampar di desa Kapota Kecamatan Wangiwangi Wakatobi pada 19 November 2018. Paus tersebut menelan sekitar 5,9kg sampah plastic yang ditemukan didalam perutnya. Paus yang panjangnya 9,5 meter itumati karena tidak bisamencerna sejumlah sampah plastic yang ditelanya seperti bungkusan mie instan,penuntup galon, botol, tali rafia dll. Lebih lanjut, hasil aksi kolaborasi lembaga lingkungan ditemukan sekitar 1,7 ton sampah plastic yang dilakukan pada bulan maret 2018. Bahkan perairan Waha pernah ditemukan 24kilogram sampah plastikoleh penyelam. Wakatobi menjadi salah satu wilayah yang Biosfer Dunia.Jadi akan sangat miris jikadisekeliling dan didlampantai masih terdapat banyak sampah plastikseperti botol,popok ataau bentuklainya.Konsekuensi dari matinya paus tersebut akan menimbulkan polusi udara dan pencemaran di lingkungan pantai. Jadi sebuah distorsi jika sebuah wilayah yang menjadi biosfer dunia tetapi pantai masih menyimpan banyaksampah plastikyang menimbulkan polusi (Kompas.com/22/11/2018). Walaupun kejadian ini telah lama terjadi dan merusak citra kota Pulau Buton tetapi masyarakat sekitar telah membangun budaya untuk menjaga laut dengan tertib. Artinya laut juga menjadi bagian dari filosofis dan budaya orang Buton. Laut adalah bukan sebuah tempat tetapi memiliki makna mendalam bagi orang Buton. Laut sdalah sumber kehidupan dan luat adalah sumber kekuasaan.

Sharing Knowledge melalui Sosialisasi Pengelolaan Sampah Plastik di Propinsi Sulawesi Tenggara 
Berbeda dengan Kabupaten Muna yang sampai saat ini belum terdengar berita bahwa terdapat sampah plastic di sejumlah pantai rekreasi di Muna. Hal ini tidak lepas dari karakter budaya orang Muna yang menjadikan laut sebagai bagian dari kehidupan mereka. Laut bukan hanya sebuah tempat rekreasi tetapi korelasi antara Muna dan laut memiliki pandangan filosofis yang menarik. Artinya orang Muna menjaga laut dengan pendekatan budaya sehingga laut tetap terjaga disaat sejumlah laut di Indonesia tercemar oleh sampah plastic.Laut di Muna terjaga dengan baik karean masyarakat sekitar mampu menjaga laut sebagai bagian dari kehidupan mereka. Sebab sebagain besar orang Muna yang tinggal dipesisir bekerja sebagai nelayan.

Objektiitas ini akan sangat menarik jika diteliti terutama dari sisi konekuensi ekonomi dan social. Oleh sebab itu penting kiranya pemerintah daerah dan aparatur pemerintah setempat untuk berkolaborasi dan menjadikan ini masalah bersama sehingga mampu merumuskan strategi komprehnsif untuk mengatasi masalah sampah plastic. Karena keindahan Wakatobi dan Muna tidak akan bisa menghasilkan devisa Negara apabila lingkungan alamnya tidak dijaga dengan baik. Artinya dalam prespektif keamanan lingkungan. Karena keamanaan aadalah bukan hanya negaranya tetapi manusia dan alamnya. Wakatobi dan Muna memiliki kemiripan karakter budaya , kultur, struktur dan postur wilayah. Sehingga laut menjadi asset yang harus dilestarikan.

\section{LITERATUR REVIEW}

Pada poin ini terbagi atas dua komponen yaitu penelitian terdahulu serta kajian teoritik sebagai prespektif analisis untuk menyelesaikan masalah.

\section{a. Penelitiaan Terdahulu}


Poin ini akan menampilkan dua hasil riset penulis terkait sampah plastic yang telah diterbitkan dalam jurnal ilmiah. Kedua penelitain yang berjudul Pengelolaan Sampah Plastik Sebagai Ancaman Keamanan Maritim Di Indonesia Di Pandegelang. Penelitian ini dilakukanpadaa tahun 2019 oleh Laode Muhamad Fathun dan I Nyoman Aji S.R dengan biaya hibah internal dari LPPM UPN Veteran Jakarta. Penelitian ini telah diterbitkan dalam jurnal Keamanan Nasional pada tahun 2019 dengan status jurnal akreditasi SINTA 3.

Adapun hasil penelitian ini adalah Kabupaten Pandegelang juga merupakan wilayah yang berdampingan dengan wilaayah laut ternyata memilikimasalah sampaah plastikyang cukupsignifikan.Hal ini terlihaat ketika terjadinya Tsunami Pandegelang pada tahun 2018, semburan Tsunami air laut mampu membawa sekitar 100 ton sampah kedarataan. Menteri Susi kala itu sampai menurunkan sekitar 100 mobil truk untuk mengangkutnya. Menurut penuturan masyarakat banyaknya sampah terjadi karena prilaku masyaraakat yang masih membuang sampah sembarangan dan tidak memiliki infrastruktur pengelolaan sampah yang baik. Konsekuensinya adalah air menjadi tercemar dan kualitas hasil tangkap juga menjadi kurang segar.

Berikutnya adalah penelitian yang berjudul The Role UCLG ASPAC In Managing Waste In DKI Jakarta Province In 2016-2019 :Opportunities And Challanges Oleh Septi Anisa, R. Dudy Heryadi dan Laode Muhamad Fathun pada tahun 2020. Penelitian ini di terbitkan dalam jurnal Tanjungpura International Journal on Dynamics Economic, Social Science and Agribusiness. Hasil penelitian ini menunjukan bahwa persoalan sampah di Jakarta sangat meresahkan. Dengan akumulasi sekitar 7 ton setiap hari Jakarta bisa saja tertimbun sampah apabila tidak terkelola dengan baik. Hal

Sharing Knowledge melalui Sosialisasi Pengelolaan Sampah Plastik di Propinsi Sulawesi Tenggara 
ini diakibatkan bukan hanya kaarena budaya tetapi tempat pembuaangan sampah juga yang semakin menipis. Jakarta haanya menghaarapkan tempat pembuangan di Bekasi yang juga menjadi tempat pembuangan kota lainya yang berdekatan dengan Bekasi. Namun dengan adanya peran UCLG pengelolaan sampah di Jakarta bisa diminimalisir salah satu tekniknya adalah dengan menjadikan sampah sebagai sumber energi listrik yang juga bisa bermanfaat bagi masyarakat.

\section{b. Kerangka Teoritik}

\section{Canadian School}

Canadian School dikutip dari (Mochamad Yani, 2017) lahir pertama kali ketika masa perang dingin yang mengakibatkan korban jiwa. Kala itu Mantan Menlu Kanada Llyod Axwothy tahun 10996 melalui kebijakan luar negerinya. Dalam prespektif ini argumentasi dasarnya adalah akibat dari memaknai keamanan yang hanya bersifat peran negara yang berhubungan dengan integritas territorial. Disisi lainya keamanan manusia semakin tidak terlindungi dengan munculnya berbagai perang sipil, perang antar agama sehingga menimbulkan banyaknya korban jiwa. Prespektif ini meujuk pada peran negara dalam melindungi warga sipil dari kekerasan. Variabel Canadian School adalah Beberapa variabel tersebut adalah: Security for whom yang artinya bagaimana melindungi warga dari ancaman apapun. Kemudian, Security what value ? ancaman dilihat dari bagaimana warga bisa memperoleh kebebasan dari Kesehatan, ekonomi, politik, pangan. Warga bisa mengakses semua itu dengan mudah. Security what thereat ? artinya ancaman yang dating dari mana apaakah dari dalam negara atau luar negara dan Security by what means? Dimaknai dengan ancaman harus diselesaikan secara bersama-sama. 
Dengan demikian perubahan ancaman keamanan yang semakin kompleks menuntut adanya strategi komprehensif darisemua pemangku kepentingan untuksaling bersinergi dalammenyelesaikan persoalan. Begitujuga dengan ancaman keamanan lingkungan akibat adanya polusi sampah plastic tentunya mengancam keamanan manusia yang berorientasi dan berkonsekueksi pada kebutuhan social, ekonomi, kesehatan dan lingkungan.

\section{ANALISIS PELAKSANAAN KEGIATAN PENGABDIAN}

Menurut Worldwide Fund for Nature (WWF) mengatakan, 300 juta ton plastik diproduksi setiap tahun dan sebagian besar berakhir di dalam bumi dan lautan ( Voa.com10/06/2019). Fakta lainya adalah sampah bermasalah ditemukan juga di batam Kepulauan Riau. Tim gabungan dari Kementerian Koordinator Bidang Kemaritiman, Kementerian Lingkungan Hidup dan Kehutanan (KLHK), Dinas Lingkungan Hidup Kota Batam, dan Kantor Pelayanan Umum Bea Cukai Batam menindak lanjuti temuan 65 kontainer sampah. Puluhan container tersebut akan diinvestigasi sehingga tidak mengandung bahan berbahaya dan beracun. Perwakilan KLHK mengusulkan perubahan Peraturan Menteri Perdagangan (Permendag) Nomor 31 Tahun 2016 tentang Ketentuan Impor Limbah Non Bahan Berbahaya dan Beracun. Kebijakan impor sampah harus detail, karena apabila tidak bisa dikenakan Undang-undang (UU) Nomor 18 Tahun 2008 tertuang dalam pasal 1 dan 2 dengan hukuman tiga tahun atau paling lama lima tahun, atau dengan biaya denda 100 juta sampai dengan lima milyar(med.com/25/06/2019).

Berdasarkan data dan analisis di atas menunjukan bahwa ancaman limbah plastic terhadap sumber kehidupan masyarakat sangat mengkhawatirkan. Artinya sampah plastic ini akan merusak tatanan social

Sharing Knowledge melalui Sosialisasi Pengelolaan Sampah Plastik di Propinsi Sulawesi Tenggara 
dan berkonsekuensi pada kehidupan masyarakat baik dalam bidang ekonomi, social dan budaya. Sehingga fakta ini adalah ancaman keamanan manusia yang nyata. Analisis wacana keamanan manusia berhubungan erat dengan bagaimana negara menyediakan kebebasan, kenyamanan, keselamatan dan kenyamanan hidup bagi warga negara. Jadi focus keamanan manusia adalah bagaimana warga negara bisa diselamatkan dari ancaman apapun.

Analisis ancaman keamanan seperti yang sudah dituliskan di atas memiliki beberapa variable yakni Security for whom. Makna dari variable ini adalah mahzab Kanada menyimpulkan bahwa keamanan menyangkut bagaimana menjaga atau melindungi warga sipil dari ancaman apapun atau sederhananya people- security - of view security. Kalau melihat operasional mahzab ini dalam pengelolaan sampah plastic di Sulawesi Tenggara dalam pendekatan budaya, warga Sulawesi Tenggara terkhusus Kabupaten Muna dan Kabupaten Buton menerapkan prinsip melindungi masyarakat dari ancaman bahaya sampah plastic. Hal ini merupakan karakter mereka.

Suku Muna dan Buton memiliki kemiripan karakter, karena dalam sejarah kedua wilayah ini adalah satu kesatuan. Penyebutan gelar kebangsaan “ La Ode " untuk laki-laki dan Wa Ode untuk perempuan adalah satu ciri khas kedua suku ini. Secara postur wilayah Kabupaten Muna dan Kabupaten Buton berbatasan langsung dengan laut bahkan sebagain kecil dari warga Muna dan Buton adalah bekerja sebagai nelayan. Di pesisir pulau biasanya hidup satu suku lagi yakni suku Bajo yang juga memiliki tradisi maritime yang baik sejak jaman dahulu . Tetapi mereka mendiami pulau Muna dan Buton untuk bersinergi dengan warga setempat. Dalam wilayah kesultanan dahulu Kerahaan Muna adalah kerajaan yang terpisah dengan Kesultanan Buton. 
Dahulu di Muna ada sebuah Kerahaan Tiworo yang kemudian pecah akibat perpecahan dalam internal kerajaan. Rajanya pada saat itu adalah Raja Lakilaponto yang merupakan salah satu Raja Muna yang beragama islam. Karena pecahnya kerajaan Muna lalu Laki Laponto melarikan diri ke Pulau Buton. Pada saat itu kerajaan Buton masih menganut animisme. Pada saat yang sama Raja Buton pada saat itu membuka sayembara untuk menaklukan seorang bajak laut bernama La Bolontio yang selalu menggangu pelayaran warga Buton. Laki Laponto beinisiatif untuk melawan bajak laut tersebut dengan hadiah mempersunting anak Raja Buton pada saat itu. Laki Laponto kemudian menang dan akhirnya mempersunting anak perempuan raja Buton dan akhirnya pula Laki Laponto menjadi Raja Buton pertama yang beragama islam.

Kekerabatan antara suku Muna dan Buton ini melahirkan kesamaan budaya sehingga dalam memaknai laut pun sebagai hal yang penting. Laut bukan hanya sebagai tempat mencari nafkah ekonomi tetapi laut juga merupakan tradisi ketangguhan warga Muna dan Buton dalam menaklukan gelombang. Selain itu, laut juga adalah identitas social warga Muna dan Buton yang selalu dijaga dan dilestarikan. Hal inilah menjadikan pantaipantai yang ada di Muna dan Buton sangat terjaga dan dipelihatra dengan baik. Ada satu filosofi orang Muna yang selalu menjadi pedoman yaitu"

Hansuru-hansuru ana badha sumonokono hansuru adhati"( boleh hancur badan asal jangan hancur adat), Hansuru-hansuru ana adhati sumanokono hansuru liwu "( boleh hancur adat asal jangan hancur wilayah) dan Hansuru-hansuru ana liwu sumanokono hansuru agama ( boleh hancur wilayah asal jangan hancur agama).

Berdasarkan prinsip di atas menunjukan bahwa orang Muna memiliki prinsip sangat Tangguh untuk menjaga adat, wilayah dan agama. Hal ini menunjukan orang Muna sangat memiliki adat yang ketantal dengan tradisi

Sharing Knowledge melalui Sosialisasi Pengelolaan Sampah Plastik di Propinsi Sulawesi Tenggara 
Dari prinsip ini bisa dismpulkan bahwa Orang Muna sangat prinsip dalam memegang filosofinya. Demikian juga dengan pengelolaan sampah plastic di Muna dan Buton. Karena mereka hidup berbatasan dengan laut maka mereka selalu menjaga wilayah tersebut dengan aman dan nyaman karena menjadi bagian dari adat. Dari kunjungan penulis di pantai Meleura Muna serta Pantai Baipas Raha serta Pantai Mutiara Buton Tengah terlihat pantai yang bersih dari sampah plastic. Sharing dengan masyarakat disana terkait konsekuensi sampah plastic, Orang Muna dan Buton sangat memahami itu sehingga tidak membuang sampah mereka di pantai karena hal pantai adalah berdampingan dengan kehidupan mereka.

Orang Muna memegang prinsip "mandehaowuto" yanag artinya mengenali diri. Orang Muna sudah mengenali dirinya sebagai bangsa pelaut yang akan terus menjaga laut sebagai tempat hidup mereka. Ini artinya bahwa penulis tanpa melakukan sosialisasi pengelolaan sampah plastic dan dampaknya pun mereka sudah memahami hal tersebut. Artinya mereka sudah menyatu dengan alam sebagai bentuk tanggung jawab social, budaya dan ekonomi. Selain itu, di Muna juga mengenal istilah " falia” sesuatu yang dilarang. Dengan membuang sampah plastic di laut berarti melanggar tradisi nenek moyang. Orang Muna percaya jika itu dilakukan dengan tujuan merusak pantai maka akan berkonsekuensi pada dirinya. Misalnya dalam orang Muna menyebutnya "Sumanga" atau sesuatu yang membuat leluhur murka. Lebih lanjut, terkait pengelolaan sampah dalam tradisi budaya Muna memegang prinsip “ kabasa” yang artinya setiap hal kesyukuran yang dilakukan oleh masyarakat Muna harus dibacakan sebagai bentuk terima kasih pada Tuhan dan tanggung jawab kepada leluhur sebagai genearis penerrus. Tradisi Kabasa ini menjadi bagian untuk menghilangkan "sumanga tadi karena keslahan pribadi”. Makanya janagan heran setiap orang luar yang 
dating ke Muna dan di Buton akan disampaikan sejumlah aturan adat agar tidak dilanggar. Kabupaten Muna membuat branding witeno wuna liwuku baraakhati kalembohano realu artinya tanahku Muna Tanah yang diberkati tempat tumpah darah. Sedangkan Buton membuata Branding Tanah Buton Barakhati Tanah Wolio. Prinsip inilah yang digunakan oleh kedua suku untuk melestarikan Muna dan Buton sehingga bisa membuat pantai bersih dan asri. Dengan demikian, bisa disimpulkan bahwa keamanan untuk siapa terjawab untuk warga Muna dan Buton itu sendiri dengan menjaga sesuai tradisi yang mereka pegang. Akhirnya mereka bisa membentuk komunitas yang saling bersinergi satu sama lainya.

Variabel Security what value, poin ini mengambil argumentasi dari UNDP yang juga pada poinya sama halnya dengan Mahzab Kanada. UNDP mengukur keamanan manusia dari safety, well- being, dignity, freedom, acces to market, and social apportunities, personal choice, surety about the future. UNDP lebih spesifik mengukurnya dari perlindungan dari ancaman penyakit, pengangguran, kelaparan, kejahatan, konflik, resiko lingkungan. Pada konteks ini tergantung pemaknaan keamanan itu untuk siapa. Berdasarkan variable di atas tentunya masyarakat pesisir Muna dan Buton memaknai laut sebagai seuatu yang ada sebagai bagian dari kehidupan. Sehingga, apapun yang ada di dasar laut, dalam laut maupun di atas laut dipergunakan sebaikbaiknya untuk kebebsan masyarakat yang bertanggung jawab. Artinya terlihat jelas bahwa masyaraakat Muna dan Buton melihat laut sebagai identiyas, potensi ekonomi, dan representasi kekuatan. Dengan menjaga laut berarti menjaga kehidupan manausiaa dan biota laut yang ada di wilayah tersebut. Dengan demikian masyarakat Muna dan Buton memahami betul cara menjaga laut kaarena menjadi bagian masa depan anak cucu yang diwariskan oleh para leluhur. Oleh sebab itulah penghargaan pada nilai

Sharing Knowledge melalui Sosialisasi Pengelolaan Sampah Plastik di Propinsi Sulawesi Tenggara 
bidaua di atas menjadi penting sebagai upaya menjaga keasrian laut agar tidak tercemar oleh prilaku manusia yang beresiko kepada lingkungan, kehidpan biota laut. Yang sering terjadi adalah aktivitas masyaraakat yang menggunakan bom buatan untuk mencari ikan di laut. Berdasarkan kunjungan dan sharing knowledge yang kamai lakukan, kami tidak menemukan aktifitas illegal tersebut. Penulis berpendapat hal ini dilakukan karena mereka menghargai prinsip nilai budaya yang sudah menjadi pedoman dan tanggung jawab Bersama. Sehingga tercipta komunitas yang saing ketergantungan dan saling menjaga sumber-sumber potensi ekonomi.

Variabel ketiga Security what thereat ini UNDP membagi asalancaman menjadi dua jenis yakni ancaman global dan ancaman local. Dalam suatu daerah kecenderungan asal ancaman bervariasi terutama menyangkut factor pembangunan ekonomi, stablias politik, kondisi geografis, Komponenen ancaman di daerah atau local biasanya menyangkut keamaman ekonomi seperti kondisi lapangan kerja, kemiskinan, kelaparan, produktivitas dan kesjateraan finansial. Selain itu menyangkut ancaman food security menyangkut factor akses mendapatkan makanan, pendapatan yang tidak stabil, makanan yang bermutu dll.Lebih lanjut aancaman health security menyangkut polusi udara, akses fasilitas kesehatan, penyakit menular. Kemudian ancaman environmental security menyangkut polusi, iklim, bencana. Dan ancaman lainya.

Berdasarkan pengamatan yang penulis lakukan bahwa sebagain besar ancaman tentang pengelolaan sampah plastic berasal dari dalam dan luar negeri. Dari dalam berasal dari prilaku masyarakat yang membuang sampah sembarangan. Sedangkan dari luar berasal dari adanya impor sampah plastic yang dilaakukan oleh sejumlah negaraa besar kepada negara-negara ASEAN. Bahkan Indonesia adalah negara dengan ancaman samapah plastic terburuk 
kedua setelah China. Artinya Indonesia berda diposisi kedua setelah China. Yang terjadi di Buton pada tahun 2018 adalah bukti Sebagian besar masyarakat sekitaran pantai. Tetapi penulis menduga bahwa kejadian tersebut banyak dilakukan oleh para pelancong wisata yang berasal dari luar. Untuk Muna sendiri belum ada peristiwa fatal seperti itu karena ancaman dari dalam daerah tidak pernah terjadi. Hal ini terjadi karena masyarakat Muna menjunjung tinggi nilai-nilai yang ada. Muna membuat tagline "Mai Te Wuna" yang artinya mari Ke Muna, tetapi sebelum ke Muna wajib kiranya memahamai adat dan budaya Muna terutama yang berhubungan dengan laut. Karena laut menjadi tempat pencaharian masyarakat Muna. Apabila hal itu dikoyori maka tentunya akan menghilangkan sumber kerja mereka, pedapatan ekonomi yang tentunya akan berimbas pada kesejateraan dan kelaparan apabila tidak dikontrol.

Dan terkhir Security by what means? variabel ini merujuk pada arguementasi UNDP terkait dengan perlunya kerjasama yang intens antar berbagai actor hubungan internasional dalam menyelesaikan keamanan manusia. UNDP mengajukan arguemntasi yaitu kseamaan konsep keamanan manusia itu sendiri calling on endorsement of the cpncept and people full contribution to global human security, Penyelesaian masalah keamanan manusia terkhusus masalah pengelolaan sampah plastic harus melalui pendekatan mikro dan maro. Pendekatan makro harus menggunanakan Kerjasama anatar negara. Apalagi keundahan pariwisata Indonesia bisa menjadi sasaran kunjungan negara lain. Dan para pengunjung berpotensi merusak laut dengan membuang sampah sembarangan. Namun jika melihat fakta Pantai di Muna dan Buton sepertinya belum menjadi lokasi orientasi pelancong manca negara. Namun tidak menutup kemungkinan di beberapa tahun kedepan jika suasana pariwisata semakin baik. Sedangkan pendekatan

Sharing Knowledge melalui Sosialisasi Pengelolaan Sampah Plastik di Propinsi Sulawesi Tenggara 
mikro dilakukan dengan kolaborasi dengan pemangku adat setempat, masyarakat serta Pemerintah setempat. Kolaborasi ini bisa membuat aturan yang bisa menjadi tata tertib pengunjung dalam berwisata di laut. Sebab banyak studi mengatakan pelancong Indonesia kurang ramah terhadap lingkungan termasuk sering membuang sampah sembarangan. Sehingga, dengan memperketat tata tertib akan semakin membuat keasrian lokasi laut yang aman, nyaman dan lestari sebagai bagian dari kehidupan. Berikut ini adalah perbedaan lokasi wisata di Muna, Buton dan Pndegelang dalam pengelolaan sampah. Dari gambar tersebut terlihat bahwa suasana pantai di Muna dan Buton lebih baik dari Kabupaten Pandegelang. Sekalipun sudah disediakan tempat sampah namun masyarakat masih tetap membuang sampah sembarangan yang tentunya mengotori dan mencemari laut dan hewan laut yang ada didalamnya.

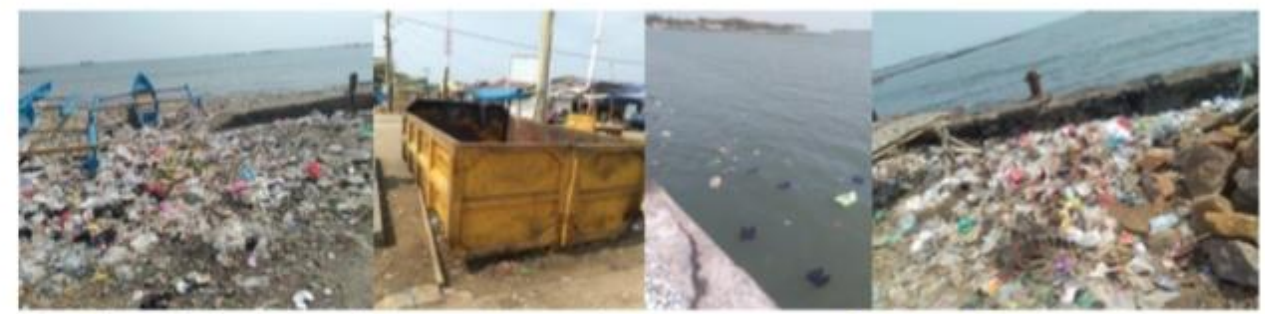

Gambar 1 lokasi pembuangan sampah di Kecamatan Labuan Pandegelang

Sumber: Fotohasil observasi lapangan

Sumber : Foto pibadi Gambar A 


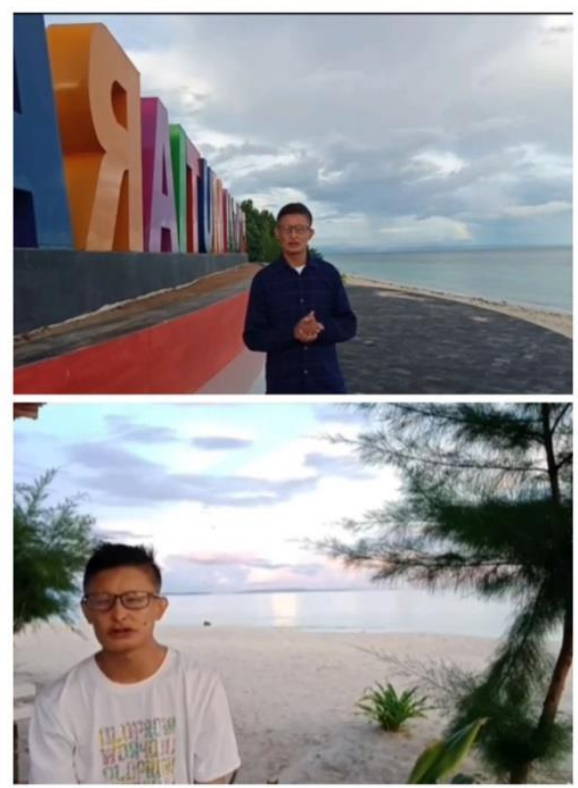

Sumber : Foto pribadi Gambar B
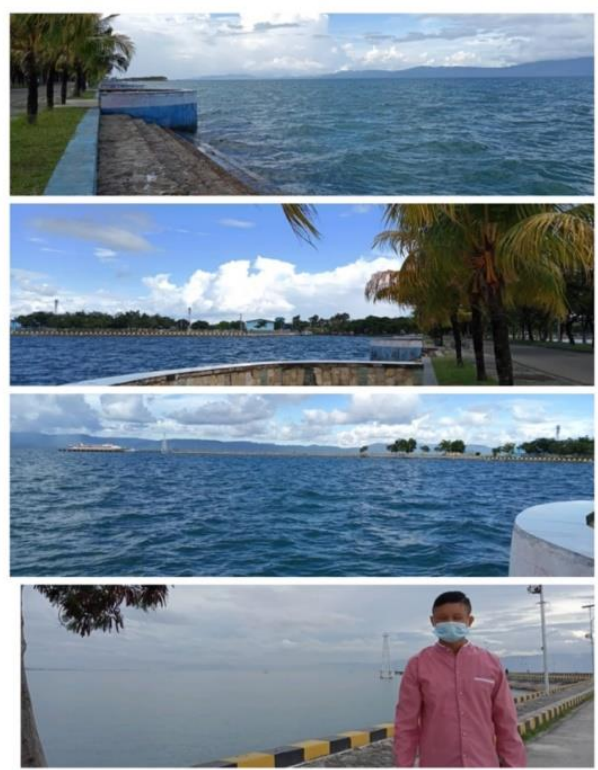

Sumber : Foto Pribadi Gambar C

Dari gaambar tersebut kita bisa belajar untuk menjaga laut dengan baik sebagai amanah Tuhan yang indah. Gambar adalah pantai yang ada di Kabupaten Pandegelang yang disekitaraan pantai dihuni oleh nelayan tradisional. Terlihat walaupun sudah disediakan tempat sampah namun pengunjung tetap membuang sampah plastic secara sembarangan. Demikian juga di gambar B adalah pantai Mutiara yang ada di Kabupaten Buton Tengah terlihat bersih dan asri tanpa ada sampah plastic yang berserakan. Sama halya dengan dengan gambar C pantai Baipas Muna tidak terlihat smapah berserakan sedikitpun. Artinya kita harus menjaga hubungan baik dengan manusia, manusia dengan alam dan manusia dengan benda mati. Pengaruh prinsip budaya kana menentukan bagaimana cara manusia berprilaku kepada alam. Penulis bersosialisasi dengan masyarakat setempat dan memang mereka sangat menjaga laut sebagai tanggung jawab moral demi anak cucu kedepan.

Sharing Knowledge melalui Sosialisasi Pengelolaan Sampah Plastik di Propinsi Sulawesi Tenggara 


\section{PENUTUP}

Berdasarkan hasil analisis Penulis dari hasil sharing knowledge melalui sosialisasi pengetahuan pengelolaan sampah plastic di Sulawesi Tenggara dalam hal ini Muna dan Buton hasilnya maksimal. Masyarakat Muna dan Buton sudah sangat paham sekali tentang menjaga laut. Mengapa, karena memaknai laut sebagai bagian dari kehidupan mereka. Laut adalah identitas, branding, sikap Tangguh dan sumber ekonomi. Sehingga, dengan membiarkan sampah plastic berseraakan di Muna atau Buton artinya masyarakat merusak masa depan mereka sendiri.

Selain itu kenapa ini bisa terjadi karena mereka menjunjung tinggi nilai moralitas adat sebagai pedoman. Mereka sangat menjaga laut sebagai titipan Tuhan yang maha kuasa. Dengan demikian, apabila tidak dijaga maka leluluhur mereka akan marah dan membutuhkan ritual-ritual khusus untuk tidak terjadi kemarahan itu. Pengunjung yang dating ke Muna dan Buton harusnya memahami aturan adat yang dipakai di daerah masing-masing sebagai upaya untuk menjaga laut. Peran tokoh adat untuk mengarahkan sangat berguna agar hubungan manusia dengan laut, mahluk laut bisa terjaga dengan baik. Selain itu pula peran pemerintah daerah juga sangat dibutuhkan sebagai pembuat regulasi dan fasilitator untuk membuat tata tertib dalam pengelolaan sampah plastic di Muna. Disana tidak dibutuhkan sampah daur ulang terkhusus sampah plastic daerah pantai karena memang tidak ditemukan sampah. 


\section{DAFTAR PUSTAKA}

Arisandi, Bustomi, Mufaizin Mufaizin, and Musohihul Hasan. "Pelatihan Pembuatan Teh Rosella dalam Meningkatkan Pendapatan Masyarakat di Desa Sorpa Kecamatan Galis Kabupaten Bangkalan." Dharma: Jurnal Pengabdian Masyarakat 1.1 (2020): 28-37.

Inu Kencana, Syafii,. Ekologi Pemerintahan Indonesia, Jakarta:Kompas Gramedia. 2019.

Haromin, Imam, Bahrul Ulum, and Abd Aziz. "Pengolahan Jahe Pandan Menjadi Produk Minuman Herbal (Japan) Untuk Meningkatkan Kualitas SDM Ekonomi Kreatif di Desa Kampak Kecamatan Geger." Dharma: Jurnal Pengabdian Masyarakat 1.1 (2020): 4960.

Kholid, Kholid, Mudarris Mudarris, and Masdar Masdar. "Olahan Kunyit Asam Menjadi Minuman Herbal Sinom untuk Meningkatkan Perekonomian Desa Kajuanak Galis Bangkalan." Dharma: Jurnal Pengabdian Masyarakat 1.1 (2020): 61-72.

Miller, S. M..J. Global Dangers Changing Dimmentions of International Security . Cambridge : MTT Press, 1995.

Mochamad Yani,Yanyan dan Ian, Moersetama. Pengantar Studi Keamanan. Malang : Intrans Publishing, 2017.

Remacle, Eric “Approaches To Human Security: Japan, Canada, And Europe In Comparative Perspective, " The Journal Social Science, 66, ( 2008)

https://www.google.com/amp/s/www.voaindonesia.com/amp/malaysiapulangkan-ratusan-ton-sampah-plastik/4952963.html

Sharing Knowledge melalui Sosialisasi Pengelolaan Sampah Plastik di Propinsi Sulawesi Tenggara 
https://m.medcom.id/amp/1bVyXwnN-pemeriksaan-65-kontainer-limbahplastik-di-batam-rampung

https://m.kumparan.com/amp/kumparanbisnis/impor-sampah-masukindonesia-ternyata-dipicu-kebijakan-china-1rIdE1zj1LJ

https://news.detik.com/berita/d-4586721/indonesia-kirim-balik-5-kontainersampah-ke-as

https://www.google.com/amp/s/amp.dw.com/id/kala-indonesia-jadi-surgapembuangan-sampah-negara-maju/a-49232628

https://www.google.com/amp/s/m.republika.co.id/amp/pscyr0348

https://www.suarasurabaya.net/tag/prigi-arisandi-direktur-eksekutif-ecoton/ https://www.google.com/amp/s/amp.kompas.com/regional/read/2018/11/22/ $\underline{\text { 15452011/5-fakta-kematian-paus-di-wakatobi-59-kg-sampah- }}$ plastik-di-perut-hingga 